\title{
Intermittent tri-weekly docetaxel plus bicalutamide in patients with castration-resistant prostate cancer: a single-arm prospective study using a historical control for comparison
}

\author{
Yun-Fei Li ${ }^{1,2, *}$, Shao-Feng Zhang ${ }^{2, *}$, Tao-Tao Zhang ${ }^{2}$, Lei Li ${ }^{1}$, Wei Gan ${ }^{2}$, Hong-Tao Jia ${ }^{2}$, Sheng Xie ${ }^{2}$, Hui-Hua Ji ${ }^{2}$ \\ and Da-Lin $\mathrm{He}^{1}$
}

Whether continuous docetaxel (DTX) chemotherapy offers an advantage over intermittent therapy for castration-resistant prostate cancer (CRPC) is unknown. In this study, we evaluated the efficacy, toxicity and quality of life (QoL) of intermittent tri-weekly DTX with bicalutamide in CRPC. Forty-two patients (group A) with CRPC were enrolled. The patients received intravenous DTX $\left(75 \mathrm{mg} \mathrm{m}^{-2}\right.$ ) once tri-weekly with oral bicalutamide $(50 \mathrm{mg})$ once daily. Patients had a DTX holiday when the prostate-specific antigen (PSA) level declined $\geqslant 50 \%$. DTX was restarted in patients with a PSA increase $\geqslant 25 \%$. Sixty patients (group B) who had matching characteristics and had continuously received DTX without bicalutamide for 10-12 cycles were also enrolled. There were no statistically significant differences in progression-free survival ( 8 months vs. 9 months, $P=0.866$ ) or overall survival ( 19 months vs. 21 months, $P=0.753$ ) between groups $A$ and $B$; however, the proportions of patients in group $A$ with all grades of neutropenia $(33 \% v s .58 \%, P=0.013)$ and nausea/vomiting ( $11 \%$ vs. $29 \%, P=0.024)$ were significantly less compared to group $B$. A significant improvement in the global health and fatigue scores was recorded for group A post-chemotherapy compared to pre-chemotherapy $(P<0.05)$. The fatigue, nausea/ vomiting and appetite loss scores in group B were increased post-chemotherapy compared to pre-chemotherapy $(P<0.05)$. In conclusion, intermittent tri-weekly DTX plus bicalutamide is well tolerated and has the potential to achieve comparable disease control with an improvement in QoL for patients with CRPC.

Asian Journal of Andrology (2013) 15, 773-779; doi:10.1038/aja.2013.89; published online 19 August 2013

Keywords: androgen; chemotherapy; docetaxel; prostate cancer; safety

\section{INTRODUCTION}

Castration-resistant prostate cancer (CRPC) is now the second most common cause of male cancer-related mortality. ${ }^{1}$ Early-stage prostate cancer can be cured by radical surgery or radiation therapy. However, approximately $10 \%-20 \%$ of men with prostate cancer have metastatic disease, and many others develop metastases despite primary treatment. $^{2,3}$ Although most patients with advanced metastatic disease initially respond to androgen deprivation with medical or surgical castration, the response to hormonal treatment lasts for a median duration of 18-24 months. Thus, most patients eventually become androgen deprivation-resistant and develop CRPC. ${ }^{4}$

Recently, data from two large phase III clinical trials (TAX327 and SWOG 9916) have shown a survival benefit for treatment with docetaxel (DTX)-containing chemotherapy regimens compared to mitoxantrone-based therapy in patients with CRPC. ${ }^{5,6}$ A maximum of 12 cycles was given in the SWOG trial, and the treatment duration in all three arms of the TAX327 trial was 10 cycles, a length of time that was arbitrarily selected. The optimal duration of this regimen has not been established; ${ }^{7,8}$ however, standard DTX chemotherapy is typically administered without pauses until unacceptable toxicity or disease progression. Thus, responding patients are exposed to uninterrupted chemotherapy for prolonged periods, with a consequent increased risk of toxicity. The potential benefit obtained with chemotherapy might be hampered by the threat of long-term toxicity. Long-term adverse effects associated with continuous DTX treatment include asthenia, oedema, peripheral neuropathy and cytopaenia. ${ }^{9}$

Intermittent chemotherapy represents an attractive therapeutic approach that might achieve comparable disease control with less toxicity and an improvement in the quality of life (QoL). Intermittent chemotherapy was first evaluated in patients with breast and colorectal cancers without adversely impacting overall survival (OS). ${ }^{10-12}$ Interestingly, not only has the lack of benefit of prolonged chemotherapy been questioned by Cara, ${ }^{13}$ Tannock $^{14}$ and Norton, ${ }^{15}$ continuous chemotherapy has also been shown to result in the 
development of chemotherapy resistance. ${ }^{8,14,16}$ Patients with CRPC who previously had discontinued DTX treatment have recently been reported to be sensitive to DTX re-treatment. ${ }^{17,18}$ Similarly, three single-arm trials have reported that the intermittent DTX approach displays comparable efficacy in patients with CRPC; ${ }^{19-21}$ however, the three trials all used weekly DTX regimens rather than a tri-weekly regimen, which has a proven benefit with an OS increase of 2.5 months compared to controls. ${ }^{5,6}$

Two important mechanisms underlying the development and progression of CRPC, which can be exploited therapeutically, are the overexpression of IL-6 and hypersensitivity or mutation of the androgen receptor, both of which contribute to CRPC. ${ }^{2-26}$ Unfortunately, the current DTX regimen does not have a role in these mechanisms. It has been demonstrated that bicalutamide (BCL) can effectively block the effect of IL- 6 on a mutated androgen receptor, resulting in the apoptosis of prostate cancer cell lines (DU-145 and LNCAP) in vitro. ${ }^{27}$ BCL alone has been shown to be safe and have some activity against CRPC. ${ }^{28-30}$ When combined with tri-weekly DTX, BCL has a synergistic effect, as confirmed by a phase III trial in androgen-dependent prostate cancer. ${ }^{31}$ In addition, a recent study reported that deferred BCL therapy could be at least partially useful after DTX failure for patients with CRPC. ${ }^{32}$

In the present study, we conducted an open-label, non-randomized, historically controlled study to evaluate the approach of intermittent DTX with BCL in patients with CRPC.

\section{MATERIALS AND METHODS}

\section{Patients and inclusion criteria}

From January 2007 to September 2012, we conducted a single-centre, prospective, open-label, non-randomized, historically controlled study in our institution with an experimental cohort of 42 patients (group A) and a retrospective control group comprising 60 patients (group B) whose inclusion and exclusion criteria matched those of the investigational group.

Eligible patients had an Eastern Cooperative Oncology Group performance status of $0-3$, histologically proven adenocarcinoma of the prostate gland and evidence of progressive metastatic disease despite androgen deprivation therapy (ADT). Specifically, progressive metastatic disease included new lesions on a bone scan or three consecutive increases in prostate-specific antigen (PSA) levels over the PSA nadir achieved by ADT separated by 2 weeks. Patients had a serum testosterone concentration $<50 \mathrm{ng} \mathrm{dl}^{-1}$ and prior treatment with maximum androgen blockade (luteinizing hormone-releasing hormone agonist or bilateral orchiectomy plus flutamide) with evidence of treatment failure. Flutamide treatment was stopped for at least 4 weeks. Patients had adequate bone marrow, liver, heart, kidney and lung function, defined as a white blood cell count $\geqslant 4000$ per $\mathrm{mm}^{3}$, granulocyte count $\geqslant 2000$ per $\mathrm{mm}^{3}$, platelet count $\geqslant 100000$ per $\mathrm{mm}^{3}$, bilirubin $\leqslant 1.5 \mathrm{mg} \mathrm{dl}^{-1}$, alanine aminotransferase and aspartate aminotransferase $\leqslant 2$ times the institutional upper limit of normal, creatinine $\leqslant 2.0 \mathrm{mg} \mathrm{dl}^{-1}$ or a calculated creatinine clearance $\geqslant 50 \mathrm{ml} \mathrm{min}^{-1}$, left ventricular ejection fraction $\geqslant 50 \%$ by echocardiography and forced expiratory volume in $1 \mathrm{~s} /$ forced vital capacity $\geqslant 70 \%$. Patients had no history of myocardial infarction within 6 months of study entry and no history of deep venous thrombosis. Patients who were previously treated with BCL and who had undergone prior secondary hormonal therapy, except for withdrawal of flutamide, were excluded. Patients who required DTX dose reduction were also excluded.

The study was performed after approval by the Human Investigations Committee of the Hubei Medical University. Informed consent was obtained from each patient.

\section{Treatment}

In group A, the patients received intravenous DTX $\left(75 \mathrm{mg} \mathrm{m}^{-2}\right)$ with dexamethasone on day 1 , oral prednisone ( $5 \mathrm{mg}$ twice daily) and BCL (50 mg once daily for 21 days during each 21-day cycle; intermittent regimen). The group B patients were administered the same tri-weekly DTX and prednisone doses continuously for 10-12 cycles without BCL (continuous regimen).

DTX chemotherapy in group A was suspended when patients achieved $a \geqslant 50 \%$ PSA decline associated with stable radiographic scans (the first three cycles of DTX were required as induction chemotherapy before the first drug holiday). During the DTX holiday, patients continued oral prednisone and BCL. DTX was restarted when the PSA level increased $\geqslant 25 \%$ or if there was any other evidence of disease progression by imaging using the Response Evaluation Criteria in Solid Tumours criteria (computed tomography scans of the thorax, abdomen and pelvis were performed every 3-6 months) and the Prostate Cancer Working Group 2 bone scan criteria (bone scans performed every 3-6 months). After chemotherapy was resumed, patients in whom the response to re-treatment met the eligibility criteria could have additional chemotherapy holidays. The number of such holidays and retreatment cycles was not restricted.

Two regimens were interrupted when disease progressed or unacceptable adverse events occurred. Treatment delays $\leqslant 2$ weeks in duration were permitted in cases of severe treatment-related toxicity. Patients were hospitalized if grade 3-4 neutropenia was observed, and granulocyte-colony stimulating factor was used for treatment.

\section{Treatment assessment}

The PSA level was assessed at baseline and every 4 weeks thereafter, and diagnostic imaging was performed every 12 weeks. The end points of this study were the time-to-PSA progression, toxicity and QoL. PSA progression was defined as a $25 \%$ increase from baseline while receiving chemotherapy and was confirmed by a second measurement 4 weeks later. Progression-free survival (PFS) was defined from the date of the first chemotherapy treatment to the date of PSA progression, which was determined in patients on intermittent chemotherapy from the start of chemotherapy to the date of chemotherapy resistance while receiving DTX. OS was calculated as the time from study entry until the date of death from any cause or censored at last follow-up. The Cancer Institute Common Toxicity Criteria (version 4.0) was used to evaluate patients for toxicity. The QoL parameters were assessed with a QoL questionnaire (European Organisation for Research and Treatment of Cancer Quality of Life Questionnaire-C30) at baseline (the day before chemotherapy was started) and every 4 weeks thereafter for 12 months after starting chemotherapy.

\section{Statistical analysis}

SPSS (version 19.0) was used for statistical analysis. Descriptive statistics were used to characterize patients at study entry and during DTX holidays. Patient age, PSA level and the interval from ADT-toCRPC were compared using the Mann-Whitney $U$ test. Other patient demographics and toxicity rates were compared using a Chi-square test. The Kaplan-Meier method was used to characterize PFS and OS. The stratified log-rank test was used to test for differences in time-toPSA progression and OS by treatment. A paired-samples $t$-test was performed to analyse the difference between pre- and post-chemotherapy scores for each QoL item. $P<0.05$ represented statistical significance (two-sided). 


\section{RESULTS}

\section{Patient characteristics}

The study included 102 patients; 42 were enrolled prospectively and 60 were selected to serve as historical controls. The patient characteristics are summarized in Table 1 . The baseline clinicopathological characteristics were generally well balanced between the two groups, and no significant differences were noted.

\section{Chemotherapy holiday}

The median follow-up period was 20 months (range, 3-24 months). In group A, 28 of the 42 patients $(66.7 \%)$ entered the first treatment holiday. Of these 28 patients, 22 had a $\geqslant 50 \%$ PSA reduction and 6 had a PSA level $<4 \mathrm{ng} \mathrm{ml}^{-1}$, which was confirmed by a second measurement 4 weeks after the first three cycles. Fourteen patients did not enter the first holiday for the following reasons: 12 patients had disease progression; 1 patient transferred to hospice care during the third DTX infusion and 1 patient had a grade 3 allergic reaction to DTX. Figure 1a shows that the median length of the first DTX holiday was 5.3 months (range: 2-20 months); two patients had first holidays of 19 and 20 months. The distribution of the duration of the first DTX holiday is shown in Figure 1b, which indicates that a significant percentage of the patients had a DTX holiday duration $\geqslant 6$ months. After the first holiday had been taken, a median of three cycles of DTX (range: 2-5) were administered, and $11(26.2 \%)$ patients qualified for a second holiday. Figure 1a shows that the median for the second holiday was 2.8 months (range: 1-7 months). Five patients (11.9\%) were permitted a third holiday, with a median duration of 1.5 months (range: $1-4$ months) after a median of two cycles of infusions (range: 2-4; Figure 1a). No patient entered a fourth DTX holiday.

\section{Chemotherapy exposure to DTX}

The median dose of DTX was $123.80 \mathrm{mg}$ (range: $101.30-140.50 \mathrm{mg}$ ) in group A and $123.65 \mathrm{mg}$ (range: $110.52-155.60 \mathrm{mg}$ ) in group B among the evaluated patients; no statistically significant difference was observed between the two groups $(P=0.287)$. The median dose intensity was $225 \mathrm{mg} \mathrm{m}^{-2}$ per 6 months (range: $225-375 \mathrm{mg} \mathrm{m}^{-2}$ per 6 months) in group A and $525 \mathrm{mg} \mathrm{m}^{-2}$ per 6 months (range: 450 $600 \mathrm{mg} \mathrm{m}^{-2}$ per 6 months) in group B; there was a statistically significant difference $(P=0.000)$ between the two groups.

\section{Toxicity}

Table 2 shows the haematological and non-haematological toxicities stratified by grade and treatment group. In group A, transient grade 3 4 neutropenia occurred in 10 patients, grade 3 febrile neutropenia occurred in 1 patient, grade 3 liver dysfunction occurred in 1 patient and a grade 4 allergic reaction was noted in 1 patient. The grade 3-4 treatment-related toxicities in group B were neutropenia (17 patients), anaemia ( 3 patients), fatigue ( 2 patients), oedema ( 2 patients), neurological issues ( 2 patients) and nausea/vomiting ( 3 patients). The patients in group A experienced a significant decrease in all grades of neutropenia ( $33 \%$ vs. $58 \%, P=0.013)$ and nausea/vomiting ( $11 \%$ vs. $29 \%, P=0.024)$. No other significant differences were noted for any grade adverse event.

\section{QoL assessment}

A significant improvement in the global health and fatigue scores was recorded for group A post-chemotherapy compared to pre-chemotherapy $(P<0.05)$. However, the symptom report scores (fatigue, nausea/vomiting, appetite loss) in group B were significantly increased post-chemotherapy compared to pre-chemotherapy $(P<0.05$; Table 3).

Table 1 Baseline characteristics of the patients

\begin{tabular}{|c|c|c|c|}
\hline Index & Group $A(n=42)$ & Group B $(\mathrm{n}=60)$ & $P$ \\
\hline Age (year), median (range) & $68(54-86)$ & $70.5(57-81)$ & 0.780 \\
\hline \multicolumn{4}{|l|}{ ECOG performance score, $n(\%)$} \\
\hline 0 & $17(40)$ & $22(37)$ & 0.697 \\
\hline 1 & $16(38)$ & $29(48)$ & 0.305 \\
\hline 2 & $5(12)$ & $6(10)$ & $1.000^{\mathrm{a}}$ \\
\hline 3 & $4(10)$ & $3(5)$ & $0.623^{\mathrm{a}}$ \\
\hline \multicolumn{4}{|l|}{ Prior treatment, $n(\%)$} \\
\hline Prostatectomy+hormonal therapy & $9(21)$ & $16(27)$ & 0.545 \\
\hline Radiotherapy+hormonal therapy & $27(64)$ & $37(62)$ & 0.788 \\
\hline Hormonal therapy & $6(14)$ & $7(12)$ & 0.696 \\
\hline AAWD response, $n(\%)$ & $10(24)$ & $16(27)$ & $0.924^{a}$ \\
\hline AAWD response time (month), median (range) & $3.15(1.50-5.57)$ & $3.46(1.00-6.47)$ & 0.493 \\
\hline \multicolumn{4}{|l|}{ Site of metastasis, $n(\%)$} \\
\hline Bone & $40(95)$ & $57(90)$ & 0.956 \\
\hline Lymph node & $12(29)$ & $18(30)$ & 0.876 \\
\hline Liver & $5(12)$ & $4(7)$ & $0.573^{\mathrm{a}}$ \\
\hline Lung & $7(17)$ & $10(17)$ & 1.000 \\
\hline Missing data & 0 & 2(3) & \\
\hline PSA (ng ml ${ }^{-1}$ ), median (range) & $63.67(12.14-1234.53)$ & $77.00(15.20-1111.48)$ & 0.854 \\
\hline \multicolumn{4}{|l|}{ Biopsy Gleason score, $n(\%)$} \\
\hline$\leqslant 6$ & $17(40)$ & $31(52)$ & 0.265 \\
\hline 7 & $12(29)$ & $10(17)$ & 0.150 \\
\hline $7-10$ & $13(31)$ & $15(25)$ & 0.507 \\
\hline Missing data & 0 & $4(7)$ & \\
\hline Time from start of ADT to CRPC (month), median (range) & $19.50(5.7-76.80)$ & $16.00(7.40-49.15)$ & 0.088 \\
\hline
\end{tabular}

Abbreviations: AAWD, anti-androgen withdrawal; ADT: androgen deprivation therapy; CRPC: castration-resistant prostate cancer; ECOG: Eastern Cooperative Oncology Group; PSA, prostate-specific antigen.

${ }^{a} P$ value from a continuity-adjusted Chi-squared test. 

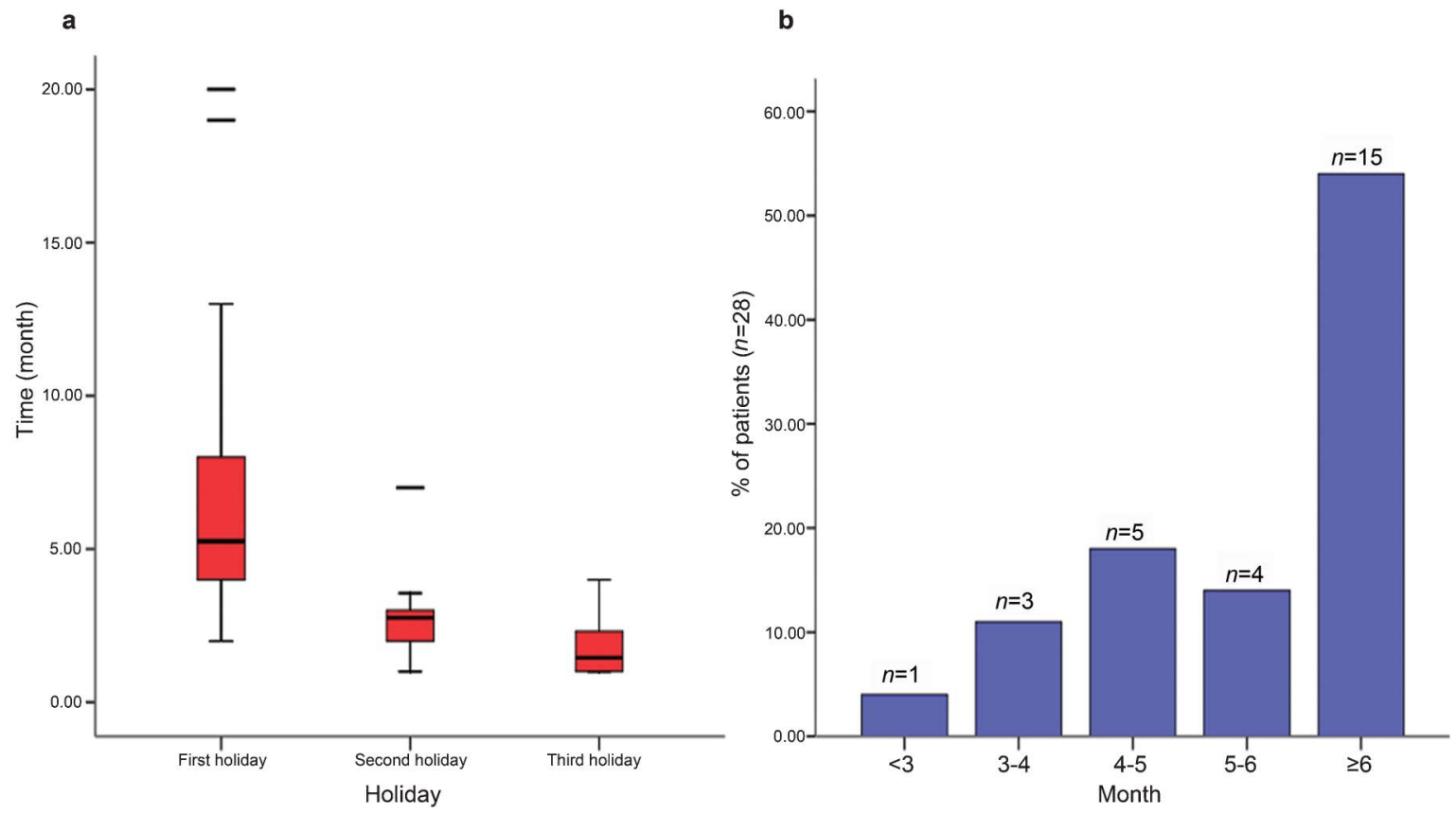

Figure 1 (a) Box plots of the docetaxel holiday for 28 patients by intermittent tri-weekly docetaxel plus bicalutamide treatment. The median of the first holiday was 5.3 months. Two patients were outliers ( 19 and 20 months) in the first holiday. The median of the second holiday was 2.8 months. One patient was an outlier ( 7 months) in the second holiday. The median of the third holiday was 1.5 months. (b) Bar chart of distribution of the first holiday for 28 patients. The first holiday lasted $\geqslant 6$ months for $50 \%$ of patients.

\section{PFS}

Figure 2a shows the PFS by treatment. The median PFS was 8 months (range: 3-23 months; 95\% CI: 6.64-9.36) in group A and 9 months (range: 2-22 months; 95\% CI: 7.93-10.07) in group B among the evaluated patients, with $16 \% \pm 6 \%$ and $21 \% \pm 6 \%$ PFS rates at 1 year in the two groups, respectively. No statistically significant difference was observed in PFS between groups A and B $(P=0.866)$.

\section{OS}

Figure 2b shows OS by treatment. The median OS was 19 months (range: 7-23 months; 95\% CI: 17.32-20.68 months) for group A and 21 months (range: 3-24 months; 95\% CI: 19.94-20.06 months) for group B. The OS rates for groups $\mathrm{A}$ and $\mathrm{B}$ were $79 \% \pm 8 \%$ and $72 \% \pm 6 \%$ at 1 year and $29 \% \pm 9 \%$ and $22 \% \pm 6 \%$ at 2 years, respectively.
There was no statistically significant difference in OS between groups A and $\mathrm{B}(P=0.753)$. Based on the present analysis, $60.7 \%(17 / 28)$ and $65 \%$ of patients $(39 / 60)$ died of prostate cancer in groups $A$ and $B$, respectively. In group A, one patient died of cerebrovascular disease. In group B, two patients died of acute myocardial infarctions, and one patient died of primary gastric cancer.

\section{DISCUSSION}

An intermittent strategy may be desirable for two reasons. First, comparable disease control and improved QoL can be achieved with less toxicity due to less cumulative chemotherapy exposure relative to continuous chemotherapy. Second, less toxic agents can be added during the chemotherapy holiday, which may increase the time of chemotherapy rest and prolong time to chemotherapy resistance.

Table 2 Adverse events of all grades, or of grade 3-4, which occurred during treatment

\begin{tabular}{|c|c|c|c|c|c|}
\hline \multirow[t]{2}{*}{ Toxicity } & \multicolumn{2}{|c|}{ Group $A(\mathrm{n}=42)$} & \multicolumn{2}{|c|}{ Group B $(\mathrm{n}=60)$} & \multirow{2}{*}{$\begin{array}{c}\text { All grades } \\
\mathrm{P}\end{array}$} \\
\hline & All grades & Grade 3-4 & All grades & Grade 3-4 & \\
\hline Neutropaenia, n (\%) & $14(33)$ & $4(10)$ & $35(58)$ & $10(17)$ & 0.013 \\
\hline Febrile neutropaenia & $1(2)$ & $1(2)$ & $3(5)$ & 0 & $0.879^{a}$ \\
\hline Anaemia & $4(10)$ & 0 & $14(35)$ & $2(3)$ & 0.072 \\
\hline Allergic reaction & $1(2)$ & $1(2)$ & $2(3)$ & 0 & $1.000^{\mathrm{a}}$ \\
\hline Fatigue & $4(10)$ & 0 & $17(28)$ & $1(2)$ & 0.021 \\
\hline Oedema & $6(14)$ & 0 & $15(25)$ & $1(2)$ & 0.188 \\
\hline Nausea/vomiting & $11(26)$ & 0 & $29(48)$ & $2(3)$ & 0.024 \\
\hline Diarrhoea & $2(5)$ & 0 & $7(12)$ & 0 & $0.392^{\mathrm{a}}$ \\
\hline Neurological & $6(14)$ & $2(5)$ & $15(25)$ & $2(3)$ & 0.118 \\
\hline Liver dysfunction & $5(12)$ & $1(2)$ & $4(7)$ & 0 & $0.573^{\mathrm{a}}$ \\
\hline Alopecia & $16(38)$ & 0 & $21(35)$ & 0 & 0.749 \\
\hline Nail change & $3(5)$ & 0 & $10(20)$ & 0 & 0.156 \\
\hline Hot flashes & $5(12)$ & 0 & $6(10)$ & 0 & $1.000^{\mathrm{a}}$ \\
\hline
\end{tabular}

${ }^{a} P$-value from a continuity-adjusted Chi-squared test. 
Table 3 Cancer quality of life (QoL) questionnaire for individual domains of the QoL with pre- and post-DTX treatment

\begin{tabular}{|c|c|c|c|c|c|c|}
\hline \multirow[b]{2}{*}{ Index } & \multicolumn{3}{|c|}{ Group $A\left(n=28^{a}\right)$} & \multicolumn{3}{|c|}{ Group $B\left(n=52^{b}\right)$} \\
\hline & Pre-DTX & Post-DTX & $\mathrm{P}$ & Pre-DTX & Post-DTX & $P$ \\
\hline Global health status $(2-14)^{c}$ & $5.69 \pm 3.28$ & $6.75 \pm 3.17$ & 0.002 & $7.40 \pm 2.48$ & $7.810 \pm 2.45$ & 0.186 \\
\hline \multicolumn{7}{|l|}{ Functional scales $^{d}$} \\
\hline Physical functioning (5-20) & $9.63 \pm 2.94$ & $9.13 \pm 2.66$ & 0.088 & $10.20 \pm 3.05$ & $9.35 \pm 2.62$ & 0.053 \\
\hline Role functioning (2-8) & $4.69 \pm 1.66$ & $4.31 \pm 1.30$ & 0.083 & $4.15 \pm 1.76$ & $3.75 \pm 1.48$ & 0.119 \\
\hline Emotional functioning (4-16) & $10.00 \pm 3.22$ & $10.75 \pm 2.70$ & 0.247 & $8.70 \pm 3.23$ & $9.80 \pm 2.93$ & 0.053 \\
\hline Social functioning (2-8) & $4.50 \pm 1.93$ & $4.69 \pm 1.74$ & 0.662 & $4.70 \pm 1.98$ & $4.50 \pm 1.47$ & 0.649 \\
\hline Cognitive functioning (2-8) & $4.50 \pm 1.03$ & $5.06 \pm 1.85$ & 0.108 & $3.90 \pm 1.89$ & $4.50 \pm 1.70$ & 0.062 \\
\hline \multicolumn{7}{|l|}{ Symptom scales ${ }^{e}$} \\
\hline Fatigue (3-12) & $6.57 \pm 1.97$ & $5.56 \pm 1.26$ & 0.034 & $5.90 \pm 1.71$ & $7.00 \pm 1.66$ & 0.007 \\
\hline Nausea and vomiting (2-8) & $2.06 \pm 0.25$ & $2.69 \pm 1.25$ & 0.076 & $2.25 \pm 0.72$ & $3.20 \pm 1.12$ & 0.004 \\
\hline Pain (2-8) & $3.87 \pm 1.78$ & $3.56 \pm 1.41$ & 0.552 & $4.20 \pm 1.61$ & $3.80 \pm 1.40$ & 0.433 \\
\hline Diarrhoea (1-4) & $1.12 \pm 0.34$ & $1.25 \pm 0.58$ & 0.497 & $1.20 \pm 0.41$ & $1.55 \pm 0.76$ & 0.110 \\
\hline Dyspnoea (1-4) & $1.13 \pm 0.34$ & $1.31 \pm 0.60$ & 0.188 & $1.15 \pm 0.49$ & $1.25 \pm 0.44$ & 0.428 \\
\hline Insomnia (1-4) & $2.75 \pm 0.68$ & $2.69 \pm 0.79$ & 0.806 & $2.75 \pm 0.79$ & $2.65 \pm 0.75$ & 0.716 \\
\hline Appetite loss (1-4) & $2.13 \pm 0.81$ & $2.31 \pm 0.79$ & 0.333 & $1.85 \pm 0.75$ & $2.45 \pm 0.60$ & 0.007 \\
\hline Financial difficulties (1-4) & $3.44 \pm 0.73$ & $3.06 \pm 0.92$ & 0.083 & $3.10 \pm 0.64$ & $3.25 \pm 0.44$ & 0.379 \\
\hline
\end{tabular}

Abbreviation: DTX: docetaxel.

a $28=42-14$ ( 14 patients did not complete the intermittent regimen).

${ }^{\mathrm{b}} 52=60-8$ ( 8 patients had missing data).

${ }^{\mathrm{c}}$ For global health status, 2 corresponded to the worst general condition and 14 corresponded to the best general condition, as perceived by the patient.

${ }^{\mathrm{d}}$ For function scales, 5 (physical functioning), 2 (role, social, cognitive) and 4 (emotional) referred to no impairment in corresponding functioning, and 20,8 and 16 corresponded to severe impairment of functioning, respectively.

${ }^{\mathrm{e}}$ For symptom scales, 3 (fatigue), 2 (nausea/vomiting, pain) and 1 (diarrhoea, dyspnoea, insomnia, appetite loss, financial difficulties) corresponded to an absence of symptoms, and 12, 8 and 4 corresponded to the most intense form of symptoms, respectively.

In the present study, the median duration of the first DTX holiday in our patients was 5.3 months, which was higher than that for patients in three single-arm phase II trials. The first two trials reported median times of 4 and 4.5 months. ${ }^{9,20}$ The third study reported a median time of 2.8 months. ${ }^{21}$ We believe that the first DTX holiday in the three trials and the present study differed for the following reasons. First, the DTX regimens differed. Beer ${ }^{9,20}$ and Miller $^{21}$ used $35 \mathrm{mg} \mathrm{m}^{-2}$ and
$36 \mathrm{mg} \mathrm{m}^{-2}$ of DTX weekly combined with calcitriol and estramustine, respectively. We administered DTX tri-weekly at a dose of $75 \mathrm{mg} \mathrm{m}^{-2}$ combined with prednisone. There are two advantages for the triweekly DTX regimen. In contrast, the two large phase III clinical trials previously described showed that tri-weekly DTX regimens demonstrated a survival benefit over mitoxantrone/prednisone (18.9 months vs. 16.4 months ${ }^{5,6}$ ); however, the weekly DTX regimen failed to
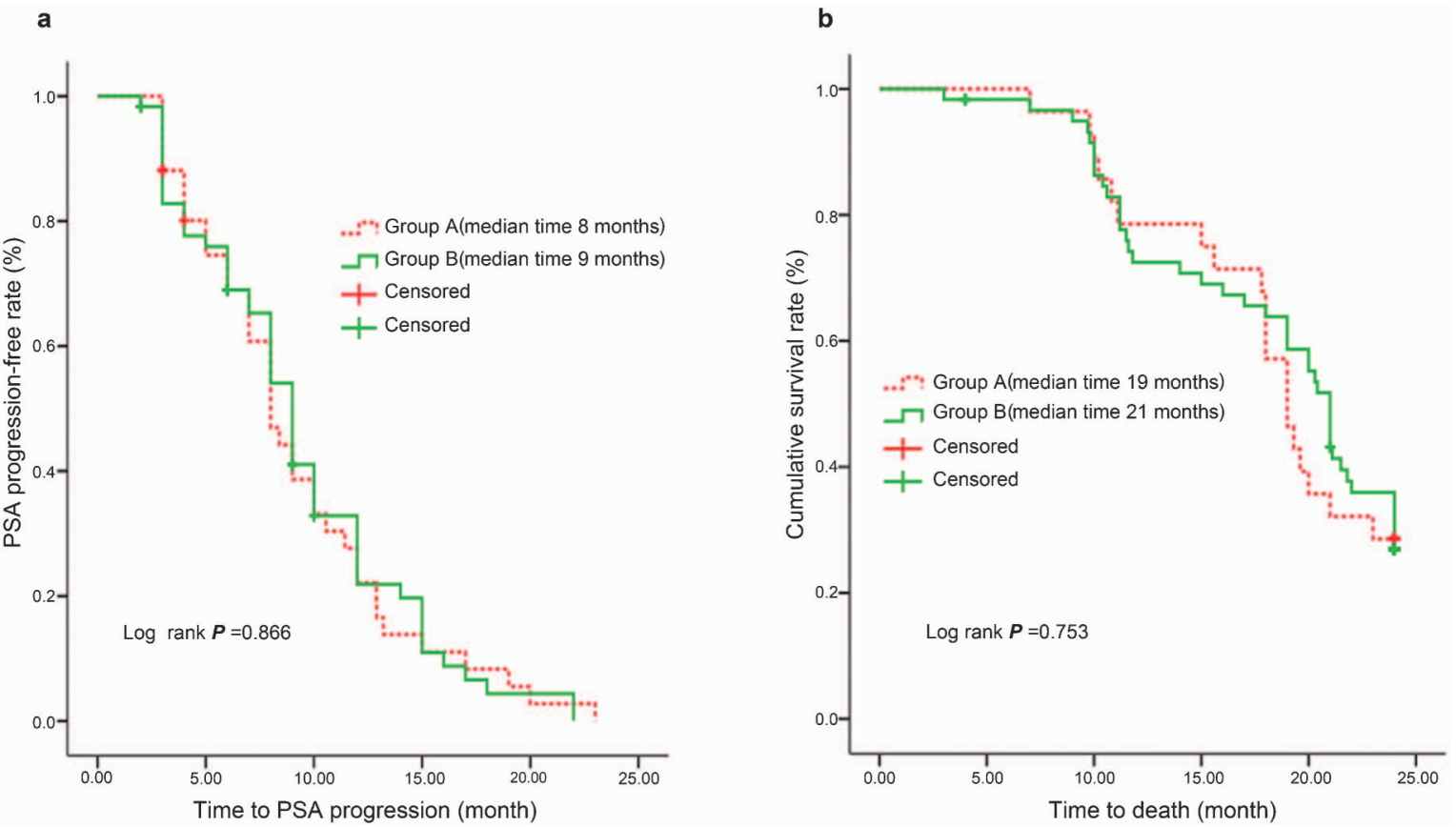

Figure 2 Kaplan-Meier estimates for time-to-PSA progression (a) and overall survival (b). PSA, prostate-specific antigen. 
provide a survival advantage over the control arm. The tri-weekly DTX/prednisone regimen had less toxicity compared with the estramustine-containing arm in the SWOG 9916 trial and potentially greater durability of QoL improvement compared to the weekly DTX arm in the TAX 327 study. Second, there were differences in patient characteristics. The amount of hormonal therapy is adversely related to the PSA response to DTX. ${ }^{33}$ Only patients with prior flutamide treatment were enrolled in our study, whereas the patients in Beer's study ${ }^{9,20}$ had received flutamide and BCL therapy. Finally, BCL might exert some activity against CRPC. The relative contribution of BCL to the intermittent therapy is analysed as follows. The use of BCL between chemotherapy periods may prevent rapid tumour re-growth and may also play a role in antitumour 'maintenance' agents in patients who have undergone initial cytoreduction with chemotherapy. Pre-clinical and clinical data have demonstrated that BCL exerts some anti-tumour activity in patients with CRPC, particularly for those previously treated long-term or who failed flutamide. ${ }^{27-29}$ Our study included patients who had previously failed flutamide. Suzuki et al. ${ }^{34}$ reported that $35.8 \%$ ( 83 of 232 ) of patients had a $>50 \%$ decline in PSA, which was observed after administering an alternative drug (flutamide was replaced by BCL) to patients with CRPC, and the decline lasted $>6$ months. In addition, tri-weekly DTX and BCL could have a synergistic effect when combined. A phase III trial reported that BCL combined with tri-weekly DTX significantly improved the PSA response and significantly reduced PSA progression at 6 months in patients with hormone-naive metastatic prostate cancer. ${ }^{31}$

In the present study, there were no significant differences between the two groups with respect to the median PFS or OS. The median OS (20 months) in group A was similar to the TAX 327 study (19.2 months ${ }^{6}$ ). This finding suggests that disease control was comparable between the intermittent tri-weekly DTX with BCL schedule and the continuous regimen. However, the median OS was significantly shorter than that reported by $\operatorname{Beer}^{20}$ (20 months vs. 41 months), who used intermittent weekly DTX plus high-dose calcitriol. This difference may have been due to different patient characteristics and different regimens; however, the median survival in our study was similar to a report by Soga ${ }^{35}$ who used tri-weekly DTX plus estramustine (20 months vs. 21 months). Similar to the results of our study, Miller $^{21}$ also reported a median overall survival of 19 months.

We intermittently administered DTX once tri-weekly plus BCL to patients with CRPC. This regimen was more convenient for patient visits than weekly visits and resulted in fewer cases of neutropenia and fatigue (all grades) compared with the continuous DTX schedule. Although it has been confirmed that long-term BCL treatment is safe even at large doses, ${ }^{36,37}$ the incidence of liver toxicity was more common in group A than group B. Thus, regular monthly determinations of liver function and timely withdrawal are required.

The QoL was significantly improved based on global health and fatigue in group A. By contrast, the continuous DTX regimen resulted in a clinically meaningful decline in QoL (fatigue, nausea/vomiting and appetite loss). An improvement in fatigue was similarly reported by Mountzios, ${ }^{38}$ who used an intermittent bi-weekly DTX schedule; however, their study lacked a control arm and did not compare the interval lengths between patients who received no chemotherapy and those treated with a secondary chemotherapy regimen. The two QoL items improved in group A for two reasons that may not be mutually exclusive because disease control in group A was comparable to group B. Additionally, this schedule had a lower DTX dose intensity due to the holiday, which reduced chemotherapy-related toxicity.
DTX-induced side effects undoubtedly diminished the patients' health status and increased their financial burden. ${ }^{39}$ In the present study, $50 \%$ of patients had a $\geqslant 6$-month DTX holiday.

Finally, we must note that the present study had several limitations, including the small number of patients and the historical controls that were associated with selection bias. In addition, intermittent DTX for CRPC is not the standard of care. In consideration of patient safety and efficacy, a group treated with intermittent DTX alone was not included; therefore, whether intermittent DTX without BCL is as effective is unknown.

\section{CONCLUSION}

Intermittent tri-weekly DTX plus BCL is well tolerated and has the potential to achieve comparable disease control with an improvement in QoL (global health and fatigue) for patients with CRPC. This strategy may be an optimal choice for patients who cannot tolerate continuous DTX chemotherapy and have a history of flutamide failure. Further prospective evaluation of a larger number of patients is warranted.

\section{AUTHOR CONTRIBUTIONS}

YFL and SFZ participated in the design of the trial, conducted the data acquisition, interpreted and statistically analyzed the data, and drafted and revised the manuscript. DLH designed the study and conducted data interpretation and revised the manuscript. WG conducted the data acquisition and designed the study. TTZ statisically analysed the data. LL designed of the trial, and HTJ, SX and HHJ interpreted the data and drafted the manuscript.

\section{COMPETING FINANCIAL INTERESTS}

The authors declare no competing financial interests.

1 Jemal A, Bray F, Center MM, Ferlay J, Ward E et al. Global cancer statistics. CA Cancer J Clin 2011; 61: 69-90.

2 Feldman BJ, Feldman D. The development of androgen-independent prostate cancer. Nature reviews. Cancer 2001; 1: 34-45.

3 Eisenberger MA, Blumenstein BA, Crawford ED, Miller G, McLeod DG et al. Bilateral orchiectomy with or without flutamide for metastatic prostate cancer. N Engl J Med 1998; 339: 1036-42.

4 Pienta KJ, Bradley D. Mechanisms underlying the development of androgenindependent prostate cancer. Clin Cancer Res 2006; 12: 1665-71.

5 Tannock IF, de Wit R, Berry WR, Horti J, Pluzanska A et al. Docetaxel plus prednisone or mitoxantrone plus prednisone for advanced prostate cancer. N Engl J Med 2004; 351: 1502-12.

6 Berthold DR, Pond GR, Soban F, de Wit R, Eisenberger M et al. Docetaxel plus prednisone or mitoxantrone plus prednisone for advanced prostate cancer: updated survival in the TAX 327 study. J Clin Oncol 2008; 26: 242-5.

7 Lin AM, Ryan CJ, Small EJ. Intermittent chemotherapy for metastatic hormone refractory prostate cancer. Crit Rev Oncol Hematol 2007; 61: 243-54.

8 Madan RA, Pal SK, Sartor O, Dahut WL. Overcoming chemotherapy resistance in prostate cancer. Clin Cancer Res 2011; 17: 3892-902.

9 Beer TM, Ryan CW, Venner PM, Petrylak DP, Chatta GS et al. Intermittent chemotherapy in patients with metastatic androgen-independent prostate cancer: results from ASCENT, a double-blinded, randomized comparison of high-dose calcitriol plus docetaxel with placebo plus docetaxel. Cancer 2008; 112: 326-30.

10 Tormey DC, Weinberg VE, Leone LA, Glidewell OJ, Perloff M et al. A comparison of intermittent vs. continuous and of adriamycin vs. methotrexate 5-drug chemotherapy for advanced breast cancer. A Cancer and Leukemia Group B study. Am J Clin Oncol 1984; 7: 231-9.

11 Maughan TS, James RD, Kerr DJ, Ledermann JA, Seymour MT et al. Comparison of intermittent and continuous palliative chemotherapy for advanced colorectal cancer: a multicentre randomised trial. Lancet 2003; 361: 457-64.

12 Muss HB, Case LD, Richards F, White DR, Cooper MR et al. Interrupted versus continuous chemotherapy in patients with metastatic breast cancer. The Piedmont Oncology Association. N Engl J Med 1991; 325: 1342-8.

13 Cara S, Tannock IF. Retreatment of patients with the same chemotherapy: implications for clinical mechanisms of drug resistance. Ann Oncol 2001; 12: 23-7.

14 Tannock IF. Tumor physiology and drug resistance. Cancer Metastasis Rev 2001; 20: 123-32. 
15 Norton L. Conceptual and practical implications of breast tissue geometry: toward a more effective, less toxic therapy. Oncologist 2005; 10: 370-81.

16 Davis AJ, Tannock IF. Tumor physiology and resistance to chemotherapy: repopulation and drug penetration. Cancer Treat Res 2002; 112: 1-26.

17 Eymard JC, Oudard S, Gravis G, Ferrero JM, Theodore C et al. Docetaxel reintroduction in patients with metastatic castration-resistant docetaxel-sensitive prostate cancer: a retrospective multicentre study. BJU Int 2010; 106: 974-8.

18 Kreis W, Budman DR, Fetten J, Gonzales AL, Barile B et al. Phase I trial of the combination of daily estramustine phosphate and intermittent docetaxel in patients with metastatic hormone refractory prostate carcinoma. Ann Oncol 1999; 10: 33-8.

19 Beer TM, Garzotto M, Henner WD, Eilers KM, Wersinger EM. Intermittent chemotherapy in metastatic androgen-independent prostate cancer. $\mathrm{Br} \mathrm{J}$ Cancer 2003; 89: 968-70.

20 Beer TM, Garzotto M, Henner WD, Eilers KM, Wersinger EM. Multiple cycles of intermittent chemotherapy in metastatic androgen-independent prostate cancer. $\mathrm{Br}$ J Cancer 2004; 91: 1425-7.

21 Miller E, Wulfing C, Lehmann J, Johannsen M, Heidenreich A et al. Weekly docetaxe plus estramustine for hormone-refractory prostate cancer (HRPC) with intermittent repetition: Preliminary results of a multicenter phase II study (AUO AP33/02). J Clin Oncol 2005; 23: 4613

22 Lee SO, Lou W, Hou M, de Miguel F, Gerber L et al. Interleukin-6 promotes androgenindependent growth in LNCaP human prostate cancer cells. Clin Cancer Res 2003; 9: 370-6.

23 Sakai I, Miyake H, Terakawa T, Fujisawa M. Inhibition of tumor growth and sensitization to chemotherapy by RNA interference targeting interleukin- 6 in the androgen-independent human prostate cancer PC3 model. Cancer Sci 2011; 102: 769-75.

24 Inoue T, Ogawa 0 . Role of signaling transduction pathways in development of castration-resistant prostate cancer. Prostate Cancer 2011; 2011: 647987.

25 Gregory CW, Johnson RT, Mohler JL, French FS, Wilson EM. Androgen receptor stabilization in recurrent prostate cancer is associated with hypersensitivity to low androgen. Cancer Res 2001; 61: 2892-8.

26 Waltering KK, Wallen MJ, Tammela TL, Vessella RL, Visakorpi T. Mutation screening of the androgen receptor promoter and untranslated regions in prostate cancer. Prostate 2006; 66: 1585-91.

27 Chen T, Wang LH, Farrar WL. Interleukin 6 activates androgen receptor-mediated gene expression through a signal transducer and activator of transcription 3-dependent pathway in LNCaP prostate cancer cells. Cancer Res 2000; 60: 2132-5.
28 Joyce R, Fenton MA, Rode P, Constantine M, Gaynes L et al. High dose bicalutamide for androgen independent prostate cancer: effect of prior hormonal therapy. J Uro 1998; 159: 149-53

29 Kucuk O, Fisher E, Moinpour CM, Coleman D, Hussain $\mathrm{MH}$ et al. Phase II trial of bicalutamide in patients with advanced prostate cancer in whom conventional hormonal therapy failed: a Southwest Oncology Group study (SWOG 9235). Urology 2001; 58: 53-8.

30 Kliment J. Words of wisdom. Re: Salvage therapy with bicalutamide $150 \mathrm{mg}$ in nonmetastatic castration-resistant prostate cancer. Lodde $\mathrm{M}$, Lacombe L, Fradet $Y$. Eur Urol 2011; 59: 1066-7.

31 Gravis G, Fizazi K, Joly F, Oudard S, Priou F et al. PSA response and early PSA progression evaluated in patients randomized in a phase III trial comparing androgendeprivation therapy (ADT) plus docetaxel versus ADT alone in hormonenaive metastatic prostate cancer (GETUG-AFU 15/0403). J Clin Oncol 2011; 29(Suppl 7): abstr 10.

32 Kijima T, Fujii Y, Yokoyama M, Ishioka J, Matsuoka Y et al. Prostate-specific antigen response to deferred combined androgen blockade therapy using bicalutamide predicts survival after subsequent oestrogen and docetaxel therapies in patients with castration-resistant prostate cancer. BJU Int 2012; 110: 1149-55.

33 Miura N, Numata K, Kusuhara Y, Shirato A, Hashine K et al. Docetaxel-prednisolone combination therapy for Japanese patients with hormone-refractory prostate cancer: a single institution experience. Jpn J Clin Oncol 2010; 40: 1092-8.

34 Suzuki H, Okihara K, Miyake H, Fujisawa M, Miyoshi S et al. Alternative nonsteroida antiandrogen therapy for advanced prostate cancer that relapsed after initial maximum androgen blockade. J Urol 2008; 180: 921-7.

35 Soga N, Kato M, Nishikawa K, Hasegawa Y, Yamada Y et al. Intermittent docetaxe therapy with estramustine for hormone-refractory prostate cancer in Japanese patients. Int J Clin Oncol 2009; 14: 130-5.

36 Soloway MS, Schellhammer PF, Smith JA, Chodak GW, Vogelzang NJ et al Bicalutamide in the treatment of advanced prostatic carcinoma: a phase I noncomparative multicenter trial evaluating safety, efficacy and long-term endocrine effects of monotherapy. J Urol 1995; 154: 2110-4.

37 Kolvenbag GJ, Blackledge GR. Worldwide activity and safety of bicalutamide: a summary review. Urology 1996; 47: 70-9; discussion 80-4.

38 Mountzios I, Bournakis E, Efstathiou E, Varkaris A, Wen S et al. Intermittent docetaxe chemotherapy in patients with castrate-resistant prostate cancer. Urology 2011; 77 682-7.

39 Zaghloul HA, Murillo JR. Treatment given near the end of life in castration-resistant prostate cancer. Am J Hosp Palliat Med 2012; 29: 536-40. 